\title{
Children and young people with intellectual disability in residential childcare: Prevalence of mental health disorders and therapeutic interventions
}

\author{
Alba Águila ${ }^{1}$, Carla González-García ${ }^{1}$, Amaia Bravo $^{1}$, Susana Lázaro-Visa ${ }^{2}$, Jorge F. del \\ Valle $^{1}$ \\ ${ }^{1}$ University of Oviedo, Spain \\ ${ }^{2}$ University of Cantabria (Spain)
}

Running title: Children with disability

Key words: intellectual disability, childcare, residential childcare, mental health, therapeutic interventions

Corresponding author:

Jorge F. Del Valle

Facultad de Psicología - Plaza Feijoo s/n, 33003 Oviedo (Spain)

Tel: +34985 103246

Fax: +34985 104144

E-mail: jvalle@uniovi.es

\section{FUNDING:}

The author Carla González García holds a predoctoral scholarship from the National Program of Training for Improving Talent and Employability in the framework of the National Plan of Scientific and Technical Research and Innovation 2013-2016 and co-financed by the European Social Fund (BES-2016-078139).

The author Alba Águila holds a pre-doctoral scholarship from the Severo Ochoa Program for training in research and teaching in Principality of Asturias (BP16061). 


\begin{abstract}
Children with Intellectual disability are more likely to suffer abuse and neglect. Therefore, they are over-represented among children in childcare interventions, particularly in residential childcare. The main goal of this article was to explore the correlates of mental health diseases in a sample of 169 children (6-18 years old) in residential care with intellectual disability compared with a group of 625 children, also in residential care but without disability. Results show that the prevalence of intellectual disability in residential childcare in Spain is about $19 \%$, which is significant due to their special needs. In addition to this disability, they have a higher frequency of clinical problems in the scales of withdrawal-depression, thought problems, attention problems and, above all, social problems than do their peers in residential care. They are also referred more frequently to therapeutic services, in particular to psychiatric intervention, and they receive more pharmacological treatments.

Key words: adolescent health and illness, child protection, residential childcare, intellectual disability, mental health treatment and services, quantitative research, Spain
\end{abstract}

\title{
Introduction
}

A large body of research shows that the prevalence of abuse of children with intellectual disability (ID) is higher than that of their peers without disability (Lightfoot, Hill, \& LaLiberte, 2011; Verdugo, Bermejo, \& Fuertes, 1995). They are two times (Sullivan \& Knutson, 1998), three times (Euser, Alink, Tharner, van Ikzendoorn, \& BakermansKranenburg, 2016; Sullivan \& Knutson, 2000) and even four times more likely to suffer some form of abuse (Barber \& Delfabbro, 2009). It is therefore not surprising that among children in out-of-home care, there is a significant representation of children with ID, which some authors have estimated to be at about 10\% (Hill, 2012; Lightfoot et al., 2011). In this 
Introduction, we review the characteristics and specific needs of these children, paying special attention to their mental health problems.

\section{Mental health problems in children and young people with ID}

The vulnerability of children and young people with ID is often aggravated by the high comorbidity with other emotional and behavioural problems (Munir, 2016; Oeseburg, Jansen, Dijkstra, Groothoff, \& Reijneveld, 2010). It was observed that they are between two and three times more likely to have mental health problems (Brondsar et al., 2011), and that around $40 \%$ meet diagnostic criteria for a mental health disorder (Dekker \& Koot, 2003; Emerson, 2003; Heneghan et al., 2013; Horwitz et al., 2013; Soltau, Biedermann, Hennicke, \& Fydrich, 2015).

Several authors have found a significant relationship between ID and an increased incidence of behavioural problems (Ahuja, Martin, Langley, \& Thapar, 2013; Embregts, du Bois, \& Graef, 2010; Myrbakk \& von Tetzchnner, 2008; Weiss, Ting, \& Perry, 2016) and anxiety (Reardon, Gray, \& Melvin, 2014). On the other hand, children with ID were found to use illegal drugs at a lower rate than those without disability, but were more vulnerable to problems arising from substance use (Carroll, Chapman, \& Wu, 2012). Specifically with regard to alcohol consumption, consequences such as the need for hospitalisation or problems with the police have been found to be more frequent among children with ID (Reis, Wetzel, \& Häßler, 2017).

As a result of these psychological and behavioural problems, people with ID are frequently prescribed psychotropic medication. Of the children and young people with ID admitted to mental health centres, $29 \%$ are estimated to take at least one psychotropic drug (Scheifes et al., 2013), antipsychotics being taken most frequently, followed by psychostimulants and anxiolytics. Another study in a population with ID living in the community found that the most commonly prescribed drugs were psycho-stimulants, antidepressants and 
antipsychotics (Doan et al., 2014). Despite the frequency with which psychotropic medication is prescribed to people with ID, empirical evidence supporting its efficacy is limited (Ji \& Findling, 2016).

The special vulnerability of these children has also been associated with the highest prevalence of abuse experiences in this population. This fact explains their overrepresentation in childcare resources.

\section{Children and young people with ID in care}

A number of studies have shown that measures involving family separation are more frequent in cases in which the children have ID problems (e.g. Chen et al., 2016; Chmelka, Trout, Mason, \& Wright, 2011; Hill, 2012; Lightfoot et al., 2011; Rosenberg \& Robinson, 2004).

After entering the care system, children with ID remain longer than their peers without disability, and are subject to more changes of placement and programmes (Chmelka et al., 2012; Hill, 2012; Sainero, Del Valle, López \& Bravo, 2013; Slayter \& Springer, 2011; Welch, Jones, Stalker, \& Stewart, 2015). They have a 38-39\% lower probability of returning to the family (Rosenberg \& Robinson, 2004; Slayter, 2016) or of adoption (Baker, 2007), and when adopted, a higher probability of adoption breakdown (Slayter \& Springer, 2011; Slayter, 2016).

The socio-demographic profile of children with ID in care is well defined, characterised by a larger presence of boys (Algood, Hong, Gourdine, \& Williams, 2011; Chmelka et al., 2011; Lightfoot et al., 2011; Oliván, 2002; Sainero et al., 2013; Slayter \& Springer, 2011, Sullivan \& Knutson, 2000; Trout et al., 2009) and a high frequency of backgrounds of mental health problems and ID in the parents (Sainero et al., 2013).

\section{Mental health problems in children and young people with ID in care}

Mental health disorders in children and young people in care (with or without ID) are two to three times more prevalent than in the general population (Bronsar et al., 2009; Hurley et al, 
2009). It was estimated that $40-80 \%$ of this group have some kind of emotional or behavioural problem (Burns et al., 2004; Pecora, Jensen, Romanelli, Jackson, \& Ortiz, 2009). In Spain, the profile of the children and young people in residential placements has changed since the 1990s, with a remarkable increase of emotional and behavioural problems (Bravo \& Del Valle, 2009). National studies show that between $44-61 \%$ of the children and young people in residential placement had clinical scores on the Child Behavioral Checklist (CBCL), and $49 \%$ were receiving mental health treatment (Sainero, Bravo \& Del Valle, 2015, González-García et al., 2017).

Although there are numerous studies on the emotional and behavioural problems of children in care, there are few studies on children with ID specifically. Trout et al. (2009) compared two groups of children in residential care, with and without ID, finding a higher score in the group with ID on almost all the CBCL scales and significant differences in the scales of Social problems and Externalizing problems. Soylu, Alpaslan, Ayaz, Esenyel, and Oruç (2013) analysed a group of children and young people with and without ID who had been victims of sexual abuse. The authors found a high presence of posttraumatic stress disorder (PTSD) in both groups, although slightly higher in the group with ID (74.5 vs. $64.9 \%)$, as well as a higher incidence of behavioural disorders in the group with ID (10.8 vs. 3.9\%). Berg, Shiu, Msall, and Acharya (2015) found that the children in their study with ID in care were twice as likely to suffer clinical depression than their peers without ID (13.8 vs. $5.5 \%$ ), observing that child depression was predicted by a history of depression in the parents, as well as distant relationships with them. In Spain, Sainero et al. (2013) also studied a sample of 264 children in residential care, finding that $18.2 \%$ had ID, almost half of whom were receiving mental health treatment - twice as many as their peers without disability as well as regular consumption of psychotropic medication (in $86.4 \%$ of the children with ID receiving treatment). 
Besides the scarcity of specific research on the mental health of children with ID in care, there are some delimitation and methodological problems. To begin with, in the research on the mental health of children in care, the term disability is used generically, covering disabilities of a diverse nature (physical, sensory and intellectual), as well as learning difficulties and behavioural and communication problems. Along the same lines, the concept of ID differs in some studies according to the criteria and the instruments used for its detection and diagnosis. Similarly, the study of the prevalence of ID in children in care is analysed more as a problem of mental health suffered by this population, and not as a group with special needs that may require specialised resources and interventions.

Based on some of these difficulties, our study had a dual goal. One goal was to analyse the mental health problems in the group of children with ID in residential childcare and the possibly associated vulnerability factors. The second goal was to analyse the therapeutic coverage they are receiving to treat these disorders. This study examined the relationship between ID and mental health problems and treatment by comparing groups of children with and without ID

\section{Method}

\section{Participants}

This sample consisted of 794 children (496 boys and 298 girls) aged between 6 and 18 ( $M=$ 13.53, $S D=2.72$ ) in residential childcare. The sample came from the regions of Asturias, Cantabria, Extremadura, Murcia, the Diputation of Guipúzcoa, the Cabildo of Tenerife, and seven Children's SOS Villages in various regions oinSpain. The sample was part of a larger research $(\mathrm{N}=1226)$, main objective of which was to analyse the prevalence of mental health problems of children in residential care in Spain and the therapeutic coverage they were receiving. The inclusion criteria to participate in this study was that the child had been living 
for at least 3 months in a residential care facility. We selected the cases that had an official diagnosis of ID $(n=169)$, given that this group was the object of analysis in this study. The rest of the group $(n=625)$ made up the sample that was selected as a comparison group. To select this matched sample, we used three criteria: the mean age and the proportion of both sexes in the two groups should be equivalent, and there should be a similar percentage of individuals with and without disabilities within each autonomous community. Furthermore, unaccompanied migrant children were excluded from these analyses, given their specific characteristics.

\section{Instruments}

The socio-familial information and case data ware obtained through a questionnaire developed ad hoc for this research, based on the System of Evaluation and Registration in Residential Placement (Bravo, Del Valle \& Santos, 2014). The following variables were included in the instrument: 1) information related to childcare intervention (time in residential placement, changes of children's home, history of foster care or adoption breakdown, and reasons for admission); 2) family background variables; and 3) the child's mental health problems and needs already detected (therapeutic care and type of treatments received).

To assess the existence of emotional and behavioural problems, we used the CBCL (Achenbach \& Rescorla, 2001). The CBCL is an instrument that shows evidence of reliability and validity, with a Cronbach alpha coefficient of .92 and test-retest reliability of .92 for the second-order scales (Achenbach et al., 2008). This instrument has been widely used in previous studies with samples of children in care (Burns et al., 2004; Greger, Myhre, Lydersen, \& Jozefiak, 2015; Jozefiak et al., 2016). The CBCL is made up of 113 items divided into eight syndrome scales (Anxiety-depression, Withdrawal-depression, Somatic complaints, Attention problems, Thought problems, Social problems, Aggressive behaviour, Disruptive behaviour) and three broadband scales (Internalizing, Externalizing, Total). In this 
study, the scores were transformed into T-scores, according to the three ranges established in the test: non-clinical $(\leq 59)$, borderline $(60 \leq 63)$, or clinical $(\geq 64)$ for the broadband Internalization, Externalization, and Total scales. In the case of the syndrome scales, the cutoff points of each range were established as non-clinical $(\leq 64)$, borderline $(65 \leq 69)$, and clinical ( $\geq 70)$. The number of cases with CBCL assessment was reduced to 771 because 23 questionnaires were discarded for not meeting the validity criteria.

\section{Procedure}

The information was gathered through each child's key residential worker (social educator). Prior to data collection, we contacted the residential children's homes to inform them about the goals of the study. The researchers and participants followed a protocol to ensure data protection and privacy. The research team, comprised of psychologists, also maintained regular contact with the educational teams in the residential facilities to ensure appropriate completion of the assessment instruments. This study received all necessary permissions from the public administrations responsible for the children's guardianship, and its design and procedure were approved by the Ethics Committee of the Faculty of Psychology of the University of Oviedo.

\section{Data analysis}

Various statistical tests were used depending on the nature of the analysed variable. For the comparative analysis between the disabled and non-disabled groups, we used the following bivariate analyses: for nominal variables, we used the chi-square statistical technique and we analysed the standardised adjusted residuals, whereas for the quantitative variables, we used Student's $t$-test.

We established $\mathrm{p} \leq .05$ as the degree of significance for all analyses. For the analysis and interpretation of the standardised adjusted residuals, we established the values lower than 
-1.95 or higher than 1.95 . All analyses were conducted using the statistical programme SPSS v24.0.

\section{Results}

\section{Characteristics and risk factors in children and families}

Table 1 presents the results of the bivariate analyses for the two groups: children with ID and without ID. After adjusting these variables in the comparison group, it can be seen that there were no significant group differences in mean age or distribution by sex.

Differences were found in ethnic group membership, with a higher percentage of ID in the group of Roma children $\chi^{2}(1, N=789)=4.72, p=.030$ and a lower percentage in children from immigrant families $\chi^{2}(1, N=790)=4.05, p=.044$.

Regarding the reasons for admission, significant differences were only observed in terms of an increased frequency of physical neglect $\chi^{2}(1, N=744)=9.44, p=.002$ and sexual abuse $\chi^{2}(1, N=743)=5.27, p=.022$ in the group with ID. A higher comorbidity of the typologies of abuse suffered was also significant in this group $(M=1.67, S D=1.41$ vs. $M=$ $1.33, S D=1.30$ for the group with ID and without ID, respectively).

Significant differences in the average stay in residential placement were also observed, with the group with ID staying almost two years longer than the group without ID $(t=-4.78$, $p \leq .001)$. Both groups had similar percentages regarding the experiences of adoption or foster care breakdown. The group with ID presented a slightly higher mean number of changes of residential placements $(M=.96, S D=.94)$ but this was not statistically significant.

With regard to family background, there was a high presence of risk factors in both groups, but a significantly higher presence of antecedents of ID $\left(42 \% ; \chi^{2}(1, N=793)=73.98\right.$, $p \leq .001)$ and mental health problems was found in the parents of the group with ID (48.5\%; $\chi^{2}(1, N=794)=27.04, p \leq .001$. In addition, the group with ID presented a higher mean 
number of risk factors in the family context than the group without ID $(M=2.20, S D=1.49$ vs. $M=1.84, S D=1.30, t=-3.07, p=.002)$.

\section{Table 1 to feature here}

\section{Physical and mental health problems and therapeutic coverage}

In the group with ID, $44.2 \%$ had an associated physical disease compared with $14.6 \%$ in the group without ID $\chi^{2}(1, N=759)=66.22, p \leq .001$. In addition, we observed that a greater proportion of children with ID were receiving speech therapy $\chi^{2}(1, N=787)=101.92, p \leq$ .001 and psychomotor skills treatment $\chi^{2}(1, N=789)=67.95, p \leq .001$.

In terms of mental health treatment, almost half of the comparison sample (46.52\%) were receiving mental health treatment (psychiatric, psychological or pharmacological), but this percentage was $72.5 \%$ in the group with ID $\chi^{2}(1, N=784)=34.40, p \leq .001$. Regarding type of treatment, children with ID were receiving both psychiatric treatment $\chi^{2}(1, N=784)=$ 69.82, $p \leq .001$ and psychopharmacological treatment $\chi^{2}(1, N=786)=97.16, p \leq .001$ more frequently. In fact, half of the sample with ID were receiving both these types of interventions. There were no significant group differences in terms of psychological treatment (see Table 2).

\section{Table 2 to feature here}

In terms of treatment characteristics (frequency, duration etc.), no significant differences were found in the type of psychiatric treatment, but it was observed that children and young people with ID had, on average, received treatment for a longer time than the group without ID $(M=39.60, S D=39.47$ vs. $M=23, S D=23.06, t=-3.23, p=.002)$.

The most common types of psychoactive drugs received by the group with ID were antipsychotics (42.2\%), psycho-stimulants (15.97\%) and anti-epileptics (14.20\%). In addition, $52.2 \%$ of the sample with ID had more than one type of psychoactive drug prescribed, with 
antipsychotics plus psycho-stimulants (25.25\%) and antipsychotics plus anti-epileptics (34\%) being the most frequent combinations.

In terms of psychological treatment, a smaller proportion of children and young people with ID were attending therapeutic programmes designed or managed from within the childcare system $\left(\chi^{2}(1, N=335)=6.29, p=.012\right)$ and the proportion receiving group treatment was higher than the group without ID $\chi^{2}(1, N=335)=10.78, p=.005$. Similarly, the group with ID had also been receiving psychological treatment for longer than the group without ID $(M=27, S D=29.67$ vs. $M=14.76, S D=16, t=-3.40, p=.001)$. No statistically significant differences were found in the rest of the treatment variables recorded.

\section{Table 3 to feature here}

Finally, no significant group differences were found with respect to suicidal behaviour; it was present at similar levels in both the group with ID (1.8\%) and the group without ID (3\%). No group differences were found in abusive consumption of alcohol, which was reported at $1.2 \%$ in young people with ID and $2 \%$ in young people without ID. However, there were group differences in the use of other substances (cannabis, heroin, inhalants and cocaine) where this problem scored $8.9 \%$ in the group with ID and $17.9 \%$ in the group without ID $\left(\chi^{2}(1, N=777)=7.24, p=.007\right.$.

\section{CBCL results}

Table 4 depicts each group's mean scores in each of the CBCL scales, along with the Student's $t$-statistic and associated significance. The group with ID scored significantly higher on the scales of Withdrawal-depression, Social problems, Thought problems, and Attention problems, as well as on the broadband Internalizing and Total scales. In contrast, the group without ID had higher scores on the Disruptive behaviour scale.

\section{Table 4 to feature here}


Analysis of the data from the CBCL in relation to cases receiving mental health treatment allowed us to assess the degree of correspondence between scores in the clinical range on this test and the therapeutic care received. As shown in Table 5, higher percentage of the group with ID were receiving treatment in almost all the clinical scales. We highlight the differences between the group with ID and the group without ID in the scales of Disruptive behaviour ( 84.2 vs. $66.7 \%$ ), Aggressive behaviour ( 83.3 vs. $65.6 \%$ ), the broadband Externalizing scales (81.7 vs. $58.5 \%)$ and the Total scale (84.1 vs. $66 \%)$. A lower percentage of clinical cases in the group with ID were receiving treatment for Thought problems (83.3 vs. $91.1 \%)$ and Social problems (80.3 vs. $86 \%)$.

\section{Table 5 to feature here}

\section{Discussion and conclusions}

We note that the high prevalence of ID observed in this sample (21.3\%) was twice that which was found previously in the international literature (Hill, 2012; Lightfoot et al., 2011). This places us squarely in the debate around the over-representation of children with disability in the child protection system and the need for research to help us understand the mechanisms

driving us towards that situation (Lightfoot et al., 2011). This debate highlights such factors as the decision-making process when choosing where to place a child, and how that may be influenced by disability, raising the chances of being referred to a fostering programme when situations of mistreatment are detected compared with minors without disability (Lightfoot et al., 2011). Many authors have indicated the urgent need to address the training of social workers in the care system to improve their skills and education about disability (Manders \& Stoneman, 2009), as well as that of educators in residential centres (Sainero et al., 2013). ID has been shown to be associated with a higher presence of mental health antecedents or ID in either of the parents, replicating findings by Sainero et al. (2013). In 
general, a greater number of family risk factors was found in the group with ID (use of intoxicating substances by parents, poverty, gender violence etc.), which reveals the vulnerability of these families.

Similarly to other international studies, we found a higher incidence of abuse in the group with ID (Lightfoot et al., 2011), as well as more types of abuse suffered simultaneously (Lightfoot et al., 2011; Sullivan \& Knutson, 1998, 2000). Analysing the most frequent types of abuse in detail, higher frequencies of physical neglect (Barber \& Delfabbro, 2009) and sexual abuse (Euser et al., 2016) were found in the group of children and young people with ID. Several authors have suggested that the risk factors associated with disability itself, such as family stress, lack of social support and low socio-economic levels could explain the higher incidence of abuse in this population (Algood et al., 2011; Berástegui \& GómezBengoechea, 2006). Specifically, the high frequency of physical neglect in this group could be associated with the need for specific care due to the presence of a disability and a lack of resources to address it. On the other hand, these data, together with the increased frequency of risk factors in these children's families, suggest the need for social services to provide better care and support in terms of the family situation in the early part of the child's development, one of the most significant challenges to the child protection system (Flynn \& McGregor, 2017).

As for the childcare intervention process, in contrast with previous studies (Hill, 2012; Slayter \& Springer, 2011; Welch et al., 2015), no significant differences in the number of changes of residential placements were found, although the results show a slightly higher mean number of changes in the group with ID. No differences in terms of the probability of having suffered family foster care or adoption breakdown were observed, as some authors have found (Baker, 2007; Slayter, 2016). On the other hand, we are in line with other studies 
(Chmelka et al., 2012; Rosenberg \& Robinson, 2004) in observing that children with ID spend nearly two years more in residential placement than do their peers without ID.

In terms of the children and young people's physical and mental health, a greater presence of physical ailments in the group with disability was observed, as well as a higher frequency of interventions in support of speech and motor skills, which is similar to findings in previous studies (Sainero et al., 2013). All of this clearly involves the use of more, and more specialized, resources for children with ID.

In our sample, we observed that children with ID present a clinical range in the CBCL more frequently than do their peers without ID, which is similar to previous findings in Spain by Sainero et al. (2013).

Taken together, these three findings - long stays in centres, more illnesses and increased incidence of mental health problems in minors with ID - would seem to be sufficient argument for better specialisation in residential care for this group, with professionals who are specially trained in disability and mental health (Sainero et al., 2013). The care system must respond both to their specific needs at the time and their often difficult transition to adult life (Harwick, Lindstrom, \& Unruh, 2017), something which is complicated enough in minors in care without mental health issues or disability The system must provide high quality services and programmes. The findings also highlight the need for better coordination between professionals in other sectors and better communication between systems, as indicated by Harwick et al. (2017).

We found significant differences in almost all the clinical scales, with higher incidence of Withdrawal-depression, Thought problems, Attention problems and, above all, Social problems. These results are consistent with those found previously by Trout et al. (2009) in a sample of children with and without ID in residential placement, where higher scores were observed in the group with ID on the scales of Anxiety-depression, Withdrawal- 
depression, Social problems and Thought problems. A higher incidence of social problems for the group of children with ID was also observed by Chmelka et al. (2012) and Sainero et al. (2013), which may indicate rejection by peers. This situation can make these children vulnerable to becoming victims of bullying, and they should be considered a risk group in this regard.

Regarding the broadband scales, a higher score was found for the group with ID in the scale of Internalizing problems, with no significant differences in Externalizing problems. Many authors have noted a higher presence of externalizing problems in young people in child protection (Keil \& Price, 2006; Schmid, Goldbeck, Nautzel, \& Fegert, 2008;

Vanschoonlandt, Vanderfaeillie, Van Holen, De Maeyer, \& Robberechts, 2013), and it seems that, in this sense, children with and those without ID do not differ. However, although both groups have similar incidences of aggressive behaviour, we found a higher frequency of disruptive behaviour in the group of children without ID.

One of the goals of this research was to analyse the therapeutic coverage provided to these children and young people for mental health issues. Regardless of whether or not they have a disability, children in care are seen by mental health services more frequently than the general population, as many authors have noted (DosReis, Zito, Safer, \& Soeken, 2001; Halfon, Mendonça, \& Berkowitz, 1995; Harman, Childs, \& Kelleher, 2000). Especially noteworthy is the frequency with which psychotropic medication is prescribed. Our results are consistent with those of Hyucksun Shin (2005) insofar as about $20 \%$ of this population were receiving some sort of psychotropic medication, a similar percentage to that obtained in our sample.

After comparing the two groups, we found referral to mental health treatment to be much more frequent in the group with ID (72.5 vs. $46.5 \%)$, underlining the higher number of referrals of these children and young people to psychiatric treatment and the high frequency 
of psychotropic medication for this population, as other authors have pointed out previously (Chmelka et al., 2012; Sainero et al., 2013).

Children with ID represent nearly one fourth of those who are in residential care in Spain, and this figure is also high in studies in other countries. However, there is little research about their specific needs. Despite being a key issue, it has received little attention in the care system, as noted by Flynn \& McGregor (2017). Our data indicate that this is a particularly vulnerable group, with specialised needs. They come from vulnerable family environments (increased incidence of mental health problems and ID) and remain in residential care for longer periods. Faced with these facts, some authors have underlined the need to ask ourselves whether this population is being well cared for by child protection services (Simmel, Merritt, Kim \& Mi-Sung Kim, 2016).

We also found this group to have a higher incidence of emotional and behavioural problems than their peers in residential care who are without ID, and that they are referred more often for psychiatric and drug treatment, as well as to speech therapy and rehabilitation. In this sense, specific assessments of these children should be required, and carried out with appropriate instruments in order to achieve early detection and referrals to the best resources. In addition, some of this group's problems may have to do with isolation and rejection by their peers in residential care, which requires specific interventions. In all probability, as Sainero et al. (2013) concluded, children with ID would benefit more from family foster care placement, and residential care placement should be avoided, as living in groups with other children is often very stressful.

Finally, we should point out that this study has some limitations. As this work is part of a larger project, the aim of which is not solely to analyse children and young people with ID, we did not use instruments adapted to the population of people with ID. Mental health pathologies do not always present the same symptoms in persons with ID as in the general 
population. However, the CBCL is a widely validated instrument that has previously been used in other studies with children and young people with ID. In the same vein, given that the project aimed at studying the characteristics of children and young people in residential care, neither IQ nor adaptive behaviour was taken into account. To avoid problems of definition, only cases that had a legally recognised ID were included in this study. Finally, as in other studies, family histories were obtained through the information of the key residential workers, which can be somewhat unreliable or incomplete.

\section{References}

Achenbach, T. M. \& Rescorla, L. (2001). Manual for the ASEBA school-age forms and profiles. Burlington, VT: University of Vermont, Research Center for Children Youths, \& Families.

Achenbach, T. M., Becker, A., Döpfner, M., Heiervang, E., Roessner, V., Steinhausen, H. C., \& Rothenberger, A. (2008). Multicultural assessment of child and adolescent psychopathology with ASEBA and SDQ instruments: Research findings, applications, and future directions. Journal of Child Psychology and Psychiatry and Allied Disciplines, 49(3), 251-275. Retrieved from https://doi.org/10.1111/j.1469-7610.2007.01867.x

Ahuja, A., Martin, J., Langley, K., \& Thapar, A. (2013) Intellectual Disability in Children with Attention Deficit Hyperactivity Disorder. The Journal of Pediatrics, 163(3), 890-895. Retrieved from https://doi.org/10.1016/j.jpeds.2013.02.043

Algood, C. L., Hong, J. S., Gourdine, R. M., \& Williams, A. B. (2011). Maltreatment of children with developmental disabilities: An ecological systems analysis. Children and Yotuh Services Review, 33(7), 1142-1148. Retrieved from https://doi.org/10.1016/j.childyouth.2011.02.003

Baker, C. (2007). Disabled Children's Experience of Permanency in the Looked After System. The British Journal of Social Work, 37(7), 1173-1188. Retrieved from https://doi.org/10.1093/bjsw/bcl082

Barber J. G. \& Delfabbro, P. H. (2009). The profile and progress of neglected and abused children in long-term foster care. Child Abuse \& Neglect, 33(7), 421-428. Retrieved from https://doi.org/10.1016/j.chiabu.2006.03.013 
Berástegui, A. \& Gómez-Bengoechea, B. (2006). Los menores con discapacidad como víctimas de maltrato infantil: una revisión [Children with disabilities as child abuse victims: a review]. Intervención Psicosocial, 15(3), 293-306.

Berg, K. L., Shiu, C. S., Msall, M. E., \& Acharya, K. (2015). Victimization and depression among youth with disabilities in the US child welfare system. Child: care, health and developmental, 41(6), 989-999. Retrieved from https://doi.org/10.1111/cch.12233

Bravo, A. \& Del Valle, J. F. (2009). Crisis and review of residential care. Its role in childhood protection. Papeles del Psicólogo, 30(1), 42-52.

Bravo, A., Del Valle, J.F., \& Santos, I. (2014). Helping Staff to Connect Quality, Practice and Evaluation in Therapeutic Residential Care: The SERAR Model in Spain. In J. Whittaker, J.F. Del Valle, y L. Holmes (ed.): Therapeutic residential care for children and youth. Exploring evidence-informed international practice, (275-287). London: Jessica Kingsley.

Bronsard, G., Lançon, C., Loundou, A., Auquier, P., Rufo, M., \& Siméoni, M. C. (2011). Prevalence rate of DSM mental disorders among adolescents living in residential group homes of the French Child Welfare System. Children and Youth Services Review, 33(10), 1886-1890. Retrieved from https://doi.org/10.1016/j.childyouth.2011.05.014

Burns, B. J., Phillips, S. D., Wagner, H. R., Barth, R. P., Kolko, D. J., Campbell, Y., \& Landsverk, J. (2004). Mental health need and access to mental health services by youths involved with child welfare: a national survey. Journal of the American Academy of Child and Adolescent Psychiatry, 43(8), 960-970.

Carroll Chapman, S. L. \& Wu, L. (2012). Substance Abuse among Individuals with Intellectual Disabilities. Research in Developmental Disabilities, 33(4), 1147-1156. Retrieved from https://doi.org/10.1016/j.ridd.2012.02.009

Chen, C. C., Culhane, D. P., Metraux, S., Park, J. M., Venable, J. C., \& Burnett, T. C. (2016). They're Not All at Home: Residential Placements of Early Adolescents in Special Education. Journal of Emotional and Behavioral Disorders, 24(4), 247-256. Retrieved from https://doi.org/10.1177/1063426615625603

Chmelka, M. B., Trout, A. L., Mason, W. A., \& Wright, T. (2011). Children with and without disabilities in residential care: risk at program entry, departure and six-month follow-up. Emotional and Behavioural Difficulties, 16(4), 383-399. Retrieved from https://doi.org/10.1080/13632752.2011.616346

Dekker, M. C. \& Koot, H. M. (2003). DSM-IV disorders in children with borderline to moderate intellectual disability. I: prevalence and impact. American Academy of Child and 
Adolescent Psychiatry, 42(8), 915-922. Retrieved from https://doi.org/10.1097/01.CHI.0000046892.27264.1A

Doan, T., Ware, R., McPherson, L., van Dooren, K., Bain, C., Carrington, S., Einfeld, S., Tonge, B. \& Lennox, N. (2014). Psychotropic medication use in adolescents with intelectual disability living in the Community. Pharmacoepidemiology and Drug Safety, 23(1), 69-76. Retrieved from https://doi.org/10.1002/pds.3484

DosReis, S., Zito, J. M., Safer D. J., \& Soeken, K. L. (2001). Mental health services for youths in foster care and disabled youths. American Journal of Public Health, 91(7), 1094-1099. Retrievet from https://doi.org/10.2105/AJPH.91.7.1094

Embregts, P. J., du Bois, M. G., \& Graef, N. (2010). Behavior problems in children with mild intellectual disabilities: an initial step towards prevention. Research in Developmental Disabilities, 31(6), 1398-1403. Retrieved from https://doi.org/10.1016/j.ridd.2010.06.020

Emerson, E. (2003). Prevalence of psychiatric disorders in children and adolescents with and without intelectual disability. Journal of Intellectual Disability Research, 47(1), 51-58.

Euser, S., Alink, L. R. Tharner, A., van Ijzendoorn, M. H., \& Bakermans-Kranenburg, M. J. (2016). The prevalence of Child Sexual Abuse in Out-of-home Care: Increased Risk for Children with a Mild Intellectual Disability. Journal of Applied Research in Intellectual Disabilities, 29(1), 83-92. Retrieved from https://doi.org/10.1111/jar.12160

Flynn S. \& McGregor C. (2017). Disabled children and child protection: learning from literature through a non-tragedy lens. Child care in Practice, 23(3), 258-274. Retrieved from https://doi.org/10.1080/13575279.2016.1259157

González-García, C., Bravo, A., Arruabarrena, I., Martín, E., Santos, I. y Del Valle, J. F. (2017). Emotional and behavioral problems of children in residential care: Screening detection and referrals to mental health services. Children and Youth Services Review, 73, 100-106, https://doi.org/10.1016/j.childyouth.2016.12.011

Greger, H. K., Myhre, A. K., Lydersen, S., \& Jozefiak, T. (2015). Previous maltreatment and present mental health in a high-risk adolescent population. Child Abuse \& Neglect, 45, 122-134. Retrieved from https://doi.org/10.1016/j.chiabu.2015.05.003

Halfon, N., Mendonça, A., \& Berkowitz, G. S. (1995). Health status of children in foster care: the experience of the Center for the Vulnerable Child. Archives of Pediatrics and Adolescent Medicine, 149(4), 386-392

Harman, J. S., Childs G. E., \& Kelleher, K. J. (2000). Mental health care utilization and expenditures by children in foster care. Archives of Pediatrics and Adolescent Medicine, 154(11), 1114-1117 
Harwick, R. M., Lindstrom, L. \& Unruh, D. (2017). In their own words: Overcoming barriers during the transition to adulthood for youth with disabilities who experienced foster care. Children and Youth Services Review, 73, 338-346. Retrieved from http://dx.doi.org/10.1016/j.childyouth.2017.01.011

Heneghan, A., Stein, R. E., Hulburt, M. S., Zhang, J., Rolls-Reutz, J., Fisher, E., Landsverk, J., \& Horwitz, S. M. (2013). Mental health problems in teens investigated by U.S. child welfare agencies. Journal of Adolescent Health, 52, 634-640. Retrieved from https://doi.org/10.1016/j.jadohealth.2012.10.269

Hill, K. M. Maltreatment and disabilities: A population-based epidemiological study. (2012). Permanency and placement planning for older youth with disabilities in out-of-home placement. Children and Youth Services, 34(8), 1418-1424. Retrieved from https://doi.org/10.1016/j.childyouth.2012.03.012

Horwitz S. M., Hulburt, M. S., Heneghan, A., Zhang, J., Rolls-Reutz, J., Landsverk, J. \& Stein, R. E. (2013). Persistence of Mental Health Problems in Very Young Children Investigated by US Child Welfare Agencies. Academic paediatrics, 13(6), 524-530. Retrieved from https://doi.org/10.1016/j.acap.2013.06.001

Hurley, K. D., Trout, A., Chmelka, M. B., Burns, B. J., Epstein, M. H., Thompson, R. W., \& Daly, D. L. (2009). The changing mental health needs of youth admitted to residential group home care: Comparing mental health status at admission in 1995 and 2004. Journal of Emotional and Behavioral Disorders, 17(3), 164-176. Retrieved from https://doi.org/10.1177/1063426608330791

Hyucksun Shin, S. (2005). Need for and actual use of mental health service by adolescents in the child welfare system. Children and Youth Services Review, 27(10), 1071-1083.

Retrieved from https://doi.org/10.1016/j.childyouth.2004.12.027

Ji, N. Y. \& Findling, R. L. (2016). Pharmacotherapy for mental health problems in people with intellectual disability. Current Opinion Psychiatry, 29(2), 103-125. Retrieved from https://doi.org/10.1097/YCO.0000000000000233

Jozefiak, T., Kayed, N. S., Rimehaug, T., Wormdal, A. K., Brubakk, A. M., \& Wichstrøm, L. (2016). Prevalence and comorbidity of mental disorders among adolescents living in residential youth care. European Child and Adolescent Psychiatry, 25(1), 33-47. Retrieved from https://doi.org/10.1007/s00787-015-0700-x

Keil, V. \& Price, J. M. (2006). Externalizing behavior disorders in child welfare settings: Definition, prevalence, and implications for assessment and treatment. Children and Youth 
Services Review, 28(7), 761-779. Retrieved from

http://dx.doi.org/10.1016/j.childyouth.2005.08.006

Lighfoot, E., Hill, K., \& LaLiberte, T. (2011). Prevalence of children with disabilities in the child welfare system and out of home placement: An examination of administrative records. Children and Youth Services Review, 33(11), 2069-2075. Retrieved from https://doi.org/10.1016/j.childyouth.2011.02.019

Manders, J. E. \& Stoneman, Z. (2009). Children with disabilities in the child protective services system: An analog study of investigation and case management. Child Abuse \& Neglect, 33, 229-237. Doi: 10.1016/j.chiabu.2008.10.001

Munir, K. M. (2016). The co-occurrence of mental disorders in children and adolescents with intellectual disability/intellectual developmental disorder. Current Opinion Psychiatry, 29(2), 95-102. Retrieved from https://doi.org/10.1097/YCO.0000000000000236

Myrbakk, E. \& von Tetzchner, S. (2008). Psychiatric disorders and behavior problems in people with intellectual disability. Research in Developmental Disabilities, 29(4), 316332, https://doi.org/10.1016/j.ridd.2007.06.002

Oeseburg, B., Jansen, D. E., Dijkstra, G. J, Groothoff, J. W., \& Reijneveld, S. A. (2010). Prevalence of chronic diseases in adolescents with intellectual disability. Research in Developmental Disabilities, 31(3), 698-704. Retrieved from https://doi.org/10.1016/j.ridd.2010.01.011

Oliván, G. G. (2002). Maltrato en niños con discapacidades: características y factores de riesgo [Maltreatment of Children with Disabilities: Characteristics and Risk Factors]. Anales Españoles de Pediatría, 56(3), 219-223.

Pecora, P. J., Jensen, P. S., Romanelli, L. H., Jackson, L. J., \& Ortiz, A. (2009). Mental Health Services for Children Placed in Foster Care: An Overview of Current Challenges. Child Welfare, 88(1), 5-26.

Reardon, T. C., Gray, K. M., \& Melvin, G. A. (2014). Anxiety disorders in children and adolescents with intellectual disability: Prevalence and assessment. Research in Developmental Disabilities, 36C, 175-190, https://doi.org/10.1016/j.ridd.2014.10.007

Reis, O., Wetzel, B., \& Häßler, F. (2017). Mild or borderline intellectual disability as a risk for alcohol consumption in adolescents - A matched-pair study. Research in Developmental Disabilities, 63, 132-141. Retrieved from https://doi.org/10.1016/j.ridd.2015.11.007 
Rosenberg, S. A. \& Robinson, C. C. (2004). Out-of-home placement for young children with developmental and medical conditions. Children and Youth Services Review, 26(8), 711723. Retrieved from https://doi.org/10.1016/j.childyouth.2004.02.016

Sainero, A., Del Valle, J. F., López, M. \& Bravo, A. (2013). Exploring the specific needs of an understudied group: Children with intellectual disability in residential child care. Children and Youth Services Review, 35(9), 1393-1399, https://doi.org/10.1016/j.childyouth.2013.04.026

Sainero, A., Del Valle, J. F. \& Bravo, A. (2015). Detección de problemas de salud mental en un grupo especialmente vulnerable: niños y adolescentes en acogimiento residencial [Detection of mental health problems in an especially vulnerable group: Children and young people in residential child care]. Anales de Psicología, 31(2), 472-480, https://doi.org/10.6018/analesps.31.2.182051

Scheifes, A., de Jong, D., Stolker, J. J., Nijman, H. L., Egberts, T. C., \& Heerdink, E. R. (2013). Prevalence and characteristics of psychotropic drug use in institutionalized children and adolescents with mild intellectual disability. Research in Developmental Disabilities, 34(10), 3159-3167. Retrieved from https://doi.org/10.1016/j.ridd.2013.06.009 Schmid, M., Goldbeck, L., Nuetzel, J., \& Fegert, J. M. (2008). Prevalence of mental disorders among adolescents in German youth welfare institutions. Child and Adolescent Psychiatry and Mental Health, 2(2). Retrieved from http://dx.doi.org/10.1186/1753-2000-2-2

Simmel, C., Merritt, D., Kim, S., \& Mi-Sung Kim, H. (2016). Developmental disabilities in children involved with Chil Welfare: Correlates of referrals for service provision. Journal of Public Chid Welfare, 10, 197-214. Retrieved from https://doi.org/10.1080/15548732.2016.1139521

Slayter, E. \& Springer, C. (2011). Child welfare-involved youth with intellectual disabilities: pathways into and placements in foster care. Intellectual and Developmental Disabilities, 49(1), 1-13. Retrieved from https://doi.org/10.1352/1934-9556-49.1.1

Slayter, E. (2016). Youth with disabilities in the United States Child Welfare System. Children and Youth Services Review, 64, 155-165. Retrieved from https://doi.org/10.1016/j.childyouth.2016.03.012

Soltau, B., Biedermann, J., Hennicke, K., \& Fydrich, T. (2015). Mental health needs and availability of mental health care for children and adolescents with intellectual disability in Berlin. Journal of Intellectual Disability Research, 59(11), 983-994. Retrieved from https://doi.org/10.1111/jir.12185 
Soylu, N., Alpaslan, A. H., Ayaz, M., Esenyel, S., \& Oruç, M. (2013). Psychiatric disorders and characteristics of abuse in sexually abused children and adolescents with and without intellectual disabilities. Research in Developmental Disabilities, 34(12), 4334-4342. Retrieved from https://doi.org/10.1016/j.ridd.2013.09.010

Sullivan, P. M. \& Knutson, J. F. (1998). The association between child maltreatment and disabilities in a hospital-based epidemiological study. Child Abuse \& Neglect, 22(4), 271288.

Sullivan, P.M., \& Knuton, J.F. (2000). Maltreatment and disabilities: A population-based epidemiological study. Child Abuse \& Neglect, 24(10), 1257-1273.

Trout, A. L., Casey, K., Chmelka, M. B., DeSalvo, C., Reid, R., \& Epstein, M. H. (2009). Overlooked: Children with Disabilities in Residential Care. Child Welfare, 88(2), 111-136.

Vanschoonlandt, F., Vanderfaeillie, J., Van Holen, F., De Maeyer, S., \& Robberechts, M. (2013). Externalizing problems in young foster children: prevalence rates, predictors and service use. Euopean Psychiatry, 28(1), 1. Retrieved from https://doi.org/10.1016/S0924$\underline{9338(13) 77107-4}$

Verdugo, M. A., Bermejo, B. G., \& Fuertes, J. (1995). The maltreatment of intellectually handicapped children and adolescents. Child Abuse \& Neglect, 19(2), 205-215.

Weiss, J. A., Ting, V., \& Perry, A. (2016). Psychosocial correlates of psychiatric diagnoses and maladaptive behaviour in youth with severe developmental disability. Journal of Intellectual Disability Research, 60(6), 583-593. Retrieved from https://doi.org/10.1111/jir.12278

Welch, V., Jones, C., Stalker, K., \& Stewart, A. (2015). Permanence for disabled children and young people through foster care and adoption: A selective review of international literature. Children and Youth Services Review, 53, 137-146. Retrieved from https://doi.org/10.1016/j.childyouth.2015.03.017 
Table 1. Differences in individual, family and care process factors.

\begin{tabular}{|c|c|c|c|}
\hline \multirow[b]{2}{*}{ Variable } & \multirow{2}{*}{$\begin{array}{c}\begin{array}{c}\text { Total } \\
(\mathrm{N}=794)\end{array} \\
\% \text { or } M(S D)\end{array}$} & \multirow{2}{*}{$\begin{array}{c}\text { ID } \\
(\mathrm{n}=169)\end{array}$} & \multirow{2}{*}{ 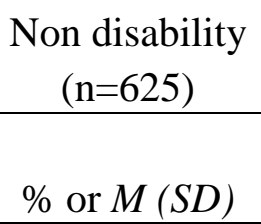 } \\
\hline & & & \\
\hline TOTAL & 100 & 21.3 & 78.7 \\
\hline \multicolumn{4}{|l|}{$\operatorname{Sex}$} \\
\hline Male & 62.5 & 62.7 & 62.4 \\
\hline Female & 37.5 & 37.3 & 37.6 \\
\hline Age & $13.53(2.71)$ & $13.88(2.66)$ & $13.44(2.72)$ \\
\hline \multicolumn{4}{|l|}{ Ethnic group } \\
\hline Roma ethnic group & 13.1 & $* * * 18.3$ & 11.6 \\
\hline Immigrant family & 12.5 & 7.7 & $* * * 13.8$ \\
\hline Mean stay (months) & $47.55(40.45)$ & $* 63.88(46.99)$ & $43.37(37.52)$ \\
\hline Break-down & 14.0 & 12.5 & 14.5 \\
\hline Foster care break-down & 12.7 & 12.5 & 12.7 \\
\hline Adoption break-down & 1.4 & - & 1.7 \\
\hline Number of changes of residential facility & $0.84(0.95)$ & $0.96(0.93)$ & $0.80(0.95)$ \\
\hline \multicolumn{4}{|l|}{ Reason for admission } \\
\hline Physical neglect & 46.8 & $* * 58$ & 43.8 \\
\hline Emotional neglect & 37.8 & 43.3 & 36.3 \\
\hline Physical abuse & 22.3 & 25.5 & 21.5 \\
\hline Emotional abuse & 27.4 & 29.9 & 26.7 \\
\hline Sexual abuse & 5.5 & $* * * 9.6$ & 4.4 \\
\hline Abandonment & 12.3 & 7.6 & 13.6 \\
\hline Out of parental control & 37.2 & 38.6 & 36.8 \\
\hline Mean reasons for admission & $1.44(1.33)$ & $* * 1.66(1.41)$ & $1.33(1.30)$ \\
\hline \multicolumn{4}{|l|}{ Family background } \\
\hline Substance abuse & 42.8 & 37.3 & 44.3 \\
\hline Mental health disorders & 31.6 & $* 48.5$ & 27 \\
\hline Criminal acts & 21.1 & 17.8 & 22 \\
\hline Intellectual disability & 18.8 & $* 42.0$ & 12.5 \\
\hline Suicide & 7.1 & 10.7 & 6.1 \\
\hline Gender violence & 27.1 & 24.3 & 27.8 \\
\hline Poverty & 43.2 & 44.1 & 40.2 \\
\hline Mean factors & $1.91(1.40)$ & $2.20(1.49)$ & $1.83(1.37)$ \\
\hline
\end{tabular}

${ }^{* * *} p \leq .05 .{ }^{* *} p \leq .01 .{ }^{*} p \leq .001$. 
Table 2. Physical and mental health characteristics.

\begin{tabular}{lrcr}
\hline & Total & \multicolumn{1}{c}{ ID } & Non disability \\
\cline { 2 - 4 } & $\mathrm{N}=794$ & $(\mathrm{n}=169)$ & $(\mathrm{n}=625)$ \\
\cline { 2 - 4 } \% or $M$ & $\%$ or $M$ & \multicolumn{2}{c}{$\%$ or $M$} \\
Variable & $(S D)$ & $(S D)$ & $(S D)$ \\
\hline Physical problems & 21.1 & $* 44.2$ & 14.6 \\
Psychomotor therapy & 3.5 & $* 14.3$ & 0.6 \\
Speech therapy & 9.4 & $* 29.9$ & 3.9 \\
Mental health treatment & 52.0 & $* 72.5$ & 46.5 \\
Psychotropic medication & 25.2 & $* 54.8$ & 17.2 \\
Psychiatric treatment & 26.9 & $* 52.7$ & 20.0 \\
Psychological treatment & 43.1 & 47.6 & 41.9 \\
Suicidal behavior & 2.7 & 1.8 & 3.0 \\
Alcohol consumption & 1.8 & 1.2 & 2.0 \\
Drug consumption & 16.0 & 8.9 & $* 17.9$ \\
\hline
\end{tabular}

$* p \leq .001$ 
Table 3. Analysis of psychological and psychiatric treatment in both samples.

\begin{tabular}{|c|c|c|c|c|}
\hline & \multicolumn{2}{|c|}{$\begin{array}{l}\text { Psychological treatment } \\
\qquad(\mathrm{N}=340)\end{array}$} & \multicolumn{2}{|c|}{$\begin{array}{l}\text { Psychiatric treatment } \\
\qquad(\mathrm{N}=211)\end{array}$} \\
\hline & $\begin{array}{c}\mathrm{ID} \\
(\mathrm{N}=80)\end{array}$ & $\begin{array}{c}\text { Non } \\
\text { disability } \\
(\mathrm{N}=260)\end{array}$ & $\begin{array}{c}\text { ID } \\
(\mathrm{N}=88)\end{array}$ & $\begin{array}{c}\text { Non } \\
\text { disability } \\
(\mathrm{N}=123) \\
\end{array}$ \\
\hline & $\begin{array}{l}\% \text { or } \mathrm{M} \\
(\mathrm{SD})\end{array}$ & $\begin{array}{c}\% \text { or } \mathrm{M} \\
(\mathrm{SD})\end{array}$ & $\begin{array}{c}\% \text { or } \mathrm{M} \\
(\mathrm{SD})\end{array}$ & $\begin{array}{c}\% \text { or } \mathrm{M} \\
(\mathrm{SD})\end{array}$ \\
\hline \multicolumn{5}{|l|}{ Type of resource providing treatment } \\
\hline Public mental health service therapist & 27.5 & 24.3 & 83.3 & 89.9 \\
\hline Private therapist & 15.0 & 9.0 & 2.4 & 0.8 \\
\hline $\begin{array}{l}\text { Therapist from specific child welfare } \\
\text { service programme }\end{array}$ & 22.5 & $* * * 38.8$ & 0 & 0 \\
\hline Staff therapist from the center & 30.2 & 33.8 & 14.3 & 9.2 \\
\hline Therapist from some other resource & 6.7 & 10.0 & 0 & 0 \\
\hline \multicolumn{5}{|l|}{ Type of therapy } \\
\hline Individual & 71.8 & 88.2 & 94.2 & 93.3 \\
\hline Group & 2.6 & 1.2 & 0 & 0.8 \\
\hline Both & 11.1 & $* 34.9$ & 5.8 & 0.8 \\
\hline \multicolumn{5}{|l|}{ Frequency of sessions } \\
\hline Weekly & 55.1 & 49.8 & 10.3 & 10.0 \\
\hline Bi-weekly & 16.7 & 23.7 & 4.6 & 4.2 \\
\hline Monthly & 7.7 & 12.9 & 18.4 & 29.2 \\
\hline Every two months & 14.1 & 6.8 & 29.9 & 33.3 \\
\hline Every three months & 3.8 & 4.4 & 19.5 & 13.3 \\
\hline Every three months & 2.6 & 2.4 & 17.2 & 10.0 \\
\hline Mean treatment & $* 29.67(3.42)$ & $16.35(1.08)$ & $* * 39.47(4.46)$ & $23.06(2.24)$ \\
\hline
\end{tabular}

${ }^{* * *} \mathrm{p} \leq .05 .{ }^{* *} \mathrm{p} \leq .01 .{ }^{*} \mathrm{p} \leq .001$. 
Table 4. Differences in CBCL scales.

\begin{tabular}{|c|c|c|c|c|c|c|}
\hline \multirow[b]{2}{*}{ Variables } & \multicolumn{2}{|c|}{ Disability (N=161) } & \multicolumn{2}{|c|}{$\begin{array}{l}\text { Non disability } \\
(\mathrm{N}=610)\end{array}$} & \multicolumn{2}{|c|}{ Difference in means } \\
\hline & $M$ & $D T$ & $M$ & $D T$ & $t$ & $p$ \\
\hline Anxiety-depression & 58.87 & 8.84 & 57.63 & 8.33 & -1.66 & 0.097 \\
\hline Withdrawal-depression & 62.72 & 9.58 & 60.26 & 9.38 & -2.94 & 0.003 \\
\hline Somatic complaints & 56.8 & 7.58 & 56.22 & 7.19 & -0.90 & 0.369 \\
\hline Social problems & 67.36 & 8.81 & 60.26 & 8.72 & -9.16 & 0.000 \\
\hline Thought problems & 60.24 & 8.71 & 56.15 & 7.61 & -5.44 & 0.000 \\
\hline Attentional problems & 65.28 & 10.07 & 61.02 & 9.62 & -4.94 & 0.000 \\
\hline Disruptive behavior & 60.65 & 8.27 & 63.24 & 9.89 & 3.05 & 0.002 \\
\hline Aggressive behavior & 64.27 & 10.81 & 64.08 & 11.60 & -0.18 & 0,855 \\
\hline Internalizing & 59.63 & 9.48 & 57.07 & 10.26 & -2.85 & 0.004 \\
\hline Externalizing & 62,49 & 9.54 & 63.09 & 11.53 & 0.60 & 0.501 \\
\hline Total & 64.14 & 7.80 & 60.96 & 10.22 & -4.29 & 0.000 \\
\hline
\end{tabular}

Table 5. Cases with clinical scores who are receiving treatment.

\begin{tabular}{lrrrr}
\hline & \multicolumn{2}{c}{ ID (N=161) } & \multicolumn{2}{c}{ Non disability (N=610) } \\
\cline { 2 - 5 } \multicolumn{1}{c}{ CBCL Scale } & $\begin{array}{c}\text { Clinical range } \\
n(\%)\end{array}$ & $\begin{array}{c}\text { Clinical cases with } \\
\text { treatment } n(\%)\end{array}$ & $\begin{array}{c}\text { Clinical range } \\
n(\%)\end{array}$ & $\begin{array}{c}\text { Clinical cases with } \\
\text { treatment } n(\%)\end{array}$ \\
\hline Anxiety-depression & $24(15.1)$ & $21(87.5)$ & $62(10.3)$ & $52(83.9)$ \\
Withdrawal-depression & $36(22.6)$ & $28(77.8)$ & $87(14.4)$ & $56(64.4)$ \\
Somatic complaints & $13(8.2)$ & $9(69.2)$ & $55(9.10)$ & $37(67.3)$ \\
Social problems & $61(38.4)$ & $49(80.3)$ & $86(14.3)$ & $74(86.0)$ \\
Thought problems & $31(19.5)$ & $26(83.9)$ & $45(7.50)$ & $41(91.1)$ \\
Attentional problems & $42(26.4)$ & $34(81.0)$ & $86(14.3)$ & $62(72.1)$ \\
Disruptive behavior & $19(11.9)$ & $16(84.2)$ & $162(26.9)$ & $108(66.7)$ \\
Aggressive behavior & $42(26.4)$ & $35(83.3)$ & $160(26.7)$ & $105(65.6)$ \\
Internalizing & $54(34.0)$ & $44(81.5)$ & $172(28.5)$ & $121(70.3)$ \\
Externalizing & $82(51.6)$ & $67(81.7)$ & $306(50.7)$ & $179(58.5)$ \\
Total & $88(55.3)$ & $74(84.1)$ & $253(42.0)$ & $167(66.0)$ \\
\hline
\end{tabular}

